\title{
Estudo dos determinantes da coleta de resíduos sólidos urbanos em Minas Gerais
}

\section{Study of the determinants of the solid waste collection in Minas Gerais, Brazil}

\author{
Magnus Martins Caldeira \\ Engenheiro Civil formado pela Universidade Federal de Minas Gerais (UFMG). Especialista em Gestão e Manejo Ambiental Agrícola pela Universidade \\ Federal de Lavras (UFLA). Mestre em Saneamento, Meio Ambiente e Recursos Hídricos pela UFMG. Engenheiro da Prefeitura de Santana do Paraíso. \\ Professor Universitário na Universidade Presidente Antônio Carlos (Unipac)
}

\begin{abstract}
Sonaly Rezende
Engenheira Civil. Mestre em Saneamento, Meio Ambiente e Recursos Hídricos pela UFMG. Doutora em Demografia pela UFMG. Professora do Departamento de Engenharia Sanitária e Ambiental da UFMG
\end{abstract}

\begin{abstract}
Léo Heller
Engenheiro Civil pela UFMG. Mestre em Engenharia Sanitária pela UFMG. Doutor em Epidemiologia pela UFMG. Professor do Departamento de Engenharia Sanitária e Ambiental da UFMG
\end{abstract}

\section{Resumo}

Este estudo teve como enfoque principal evidenciar a realidade mais ampla da situação da coleta de resíduos sólidos urbanos (RSU) em Minas Gerais em 2000, trazendo aportes para este campo de análise por envolver as variáveis demográficas e socioeconômicas que ajudam na caracterização dos aspectos relativos à demanda e à oferta do serviço, por meio da modelagem hierárquica. Seus resultados permitiram delinear um perfil daqueles que não têm acesso ao serviço de coleta e habitam principalmente as pequenas cidades das regiões mais pobres do Estado e as periferias urbanas dos grandes centros, representando a parcela populacional mais pobre e menos escolarizada, com acesso limitado também ao conhecimento e à saúde.

Palavras-chave: coleta de resíduos sólidos urbanos; análise hierárquica; oferta; demanda.

\section{Abstract}

The main goal of this paper was to address the picture of urban solid wastes collection in the State of Minas Gerais, Brazil, in 2000 . A hierarchical analysis was performed as considering demographic and socioeconomic variables and the demand and supply dimensions of such services. The study was able to identify the profile of the population that has no access to these services in the State, who inhabit mainly small villages in the poorest regions and slums in the largest cities, representing the poorest and less literate portion of the population, with limited access to culture and to health services.

Keywords: solid waste collection; hierarchical model; supply; demand.

\section{Introdução}

Em janeiro de 2007, o Setor de Saneamento do Brasil conheceu seu marco de referência, definido pela lei 11.445, que contém as "Diretrizes Nacionais para o Saneamento Básico" (BRASIL, 2007). Este texto trata dos mais diversos aspectos concernentes ao setor, incorporando e integrando conceitos, princípios e diretrizes relativos aos serviços públicos de abastecimento de água, esgotamento sanitário, drenagem urbana e manejo de resíduos sólidos. Para esta última temática, a referida lei estabelece atividades de coleta, transporte, transbordo, tratamento e disposição final dos resíduos sólidos domésticos.
A titularidade dos serviços públicos de saneamento pertence aos municípios, assim foi definido no texto da Constituição Federal de 1988 (BRASIL, 2005). As prefeituras e a coletividade têm o dever de prover o acesso de toda a população à adequadas soluções sanitárias, promovendo, deste modo, boas condições de saúde pública e de qualidade ambiental aos habitantes. No entanto, esta realidade está fora do alcance de uma parcela significativa da população brasileira, que não é atendida pelos serviços. A carência na cobertura se faz sentir, majoritariamente, nas áreas urbanas de precária infraestrutura das grandes cidades, assim como nos pequenos municípios, onde a disponibilidade de recursos financeiros e humanos é limitada. Os impactos negativos desta ausência e/ou precariedade de atendimento 
aos domicílios são bem reportados pela literatura, e vale destacar a maior incidência de doenças bem como as consequências sociais e econômicas para as famílias afligidas.

Pretende-se, neste estudo, apresentar um quadro com os principais determinantes da coleta domiciliar de resíduos sólidos urbanos (RSU) em Minas Gerais, considerando a distinção entre os aspectos relativos à oferta e à demanda desses serviços. A análise foi realizada com base em dados do IBGE (2000A; 2000B), sendo as variáveis de demanda, cuja unidade de referência é o domicílio, selecionadas na base de dados do Censo Demográfico de 2000 (IBGE, 2000A); as variáveis que caracterizam a oferta têm como referência as unidades municipais e foram criadas a partir dos dados da Pesquisa Nacional de Saneamento Básico de 2000 (IBGE, 2000B).

Realizou-se a análise quantitativa dos dados em duas etapas: a primeira, mais descritiva e de caráter exploratório; a segunda, estatística, envolveu a análise hierárquica que pretendeu separar os efeitos de demanda dos de oferta, evidenciando os aspectos que são determinantes pela existência do serviço de coleta de RSU.

\section{A cobertura dos serviços de saneamento e seus determinantes}

São vários os autores que abordam a questão da cobertura dos serviços de saneamento no Brasil e, em geral, apontam um quadro de carência na prestação destes serviços. Costa (2007), por exemplo, dissertando sobre aspectos conjunturais do saneamento no Brasil, destaca que, apesar de a cobertura dos serviços ter aumentado recentemente, ainda existe uma considerável parcela da população urbana fadada à exclusão sanitária. Essa população é constituída pelas camadas de renda mais baixa e que, em geral, habitam áreas precárias sob o ponto de vista da adequada infraestrutura urbana. Lopes, Macedo e Machado (2003), realizando uma abordagem multidimensional da pobreza, corroboram esta visão e afirmam que o entendimento das diversas dimensões socioeconômicas da exclusão social é importante quando se almeja solucionar o déficit de cobertura dos serviços públicos prestados à população. Os autores também argumentam que, mesmo entre os excluídos, existem diferenças significativas, especialmente quando se aborda a questão da dicotomia urbanorural, além das disparidades entre as regiões administrativas e/ou de planejamento.

Outros autores alertam para a importância do aspecto "qualidade" para se ter uma visão real da cobertura dos serviços de saneamento. Heller (1999), ao analisar a prestação os serviços de saneamento na cidade de Betim, mostrou que apenas a obtenção dos valores proporcionais de cobertura dos serviços públicos do setor não seria suficiente para se apreender adequadamente a dinâmica dos mesmos. Tais análises deveriam levar em conta se os referidos serviços estavam sendo prestados satisfatoriamente à população, quais seriam as soluções adotadas por aqueles que não possuíam acesso aos serviços formais e quais as consequências para a saúde e a qualidade de vida dessas pessoas.

Estudando a questão das políticas do setor de saneamento, Dias, Borja e Moraes (2004) apresentam as condições sanitárias em áreas de ocupação espontânea, revelando a forte correlação da distribuição espacial da população com os padrões de desigualdade social, que estariam associados às disparidades socioeconômicas características do País. Segundo os autores, o entendimento desses aspectos deve ser relacionado às condições sanitárias existentes para melhor subsidiar os processos de formulação e consolidação das políticas públicas de saneamento nos assentamentos carentes de serviços públicos essenciais.

Heller e Castro (2007) afirmam que, para um melhor entendimento da dinâmica de ações e resultados do setor de saneamento, deve-se somar à abordagem tecnológica o caráter de política pública setorial que o saneamento apresenta. Tal conjunção de visões é que poderá levar à proposição de soluções que podem eliminar o déficit de cobertura dos serviços públicos, pois a mera alegação de falta de recursos financeiros não fundamenta esta carência de atendimento. Os autores conferem importância ao entendimento dos condicionantes sistêmicos, que são os processos sociais, políticos, econômicos, culturais e demográficos que determinam tanto as políticas quanto os seus beneficiários.

Rezende (2002), analisando a relação entre as migrações internas e as políticas de saneamento no Brasil, evidencia a existência de extremas desigualdades regionais e socioeconômicas no acesso aos serviços públicos, o que incide na proliferação de doenças infecciosas e parasitárias, sobretudo nas áreas mais pobres das regiões metropolitanas e nas áreas rurais mais isoladas. A autora destaca como as políticas econômicas predominantes em cada contexto histórico condicionam os processos demográficos no Brasil e, como estes, por sua vez, têm sido determinantes para as políticas públicas setoriais, como as de saneamento.

Ao analisarem a gestão ambiental em resíduos sólidos no Brasil, Brollo e Silva (2001) apontaram a existência de um quadro de degradação social e ambiental, em especial nas áreas de mais baixa renda, onde grande parcela da população convivia com a ausência da coleta dos resíduos sólidos e/ou sua disposição inadequada em terrenos ou cursos d'água próximos. A ausência ou irregularidade na coleta domiciliar dos resíduos sólidos tem sido apontada como uma grande falha da atuação municipal no gerenciamento dos resíduos sólidos. De acordo com Monteiro et al. (2001), esta realidade é especialmente visível nas áreas onde habitam as camadas sociais de mais baixa renda e no dia-a-dia dos municípios menos desenvolvidos economicamente.

Compartilha desta constatação D'Almeida (2000), que também afirma que a composição e a quantidade de resíduos sólidos gerados nos municípios estão associadas ao seu porte populacional e grau de desenvolvimento econômico. Esses autores destacam os desafios relativos ao manejo dos resíduos sólidos em grandes centros urbanos, 
onde a quantidade de resíduos sólidos gerados e a dificuldade de se viabilizarem áreas para sua disposição são aspectos de máxima relevância, assim como em pequenas cidades, graças às carências financeiras e administrativas que lhes são peculiares.

A fragilidade dos mecanismos legais e econômicos e das práticas institucionais no País, que levam a uma realidade de ausência de serviços públicos eficientes e sustentáveis em muitos municípios, tem trazido consequências negativas para a saúde da população. O estudo de Heller e Catapreta (1999), contendo uma análise da relação entre a coleta de RSU e a saúde pública, indica a existência de associação entre o manejo inadequado dos resíduos e a incidência de doenças infecciosas e parasitárias. A ausência de coleta dos resíduos sólidos somada à sua disposição inadequada constitui um importante fator de risco para a saúde pública, em especial nas periferias dos grandes centros urbanos, onde a população de mais baixa renda se encontra fortemente exposta aos riscos associados às enfermidades.

\section{Metodologia}

Neste estudo, buscou-se a composição do panorama da cobertura e da disposição final dos RSU em Minas Gerais por meio da análise quantitativa dos dados do IBGE referentes ao Censo Demográfico de 2000 (IBGE, 2000A) e à Pesquisa Nacional de Saneamento Básico de 2000 (IBGE, 2000B). Para a situação específica da coleta, realizou-se modelagem estatística com análise hierárquica, visando a captar o efeito das variáveis de maior poder preditivo, definidos dois níveis hierárquicos: o domiciliar e o municipal. Foram incluídas, na análise hierárquica, variáveis geográficas, socioeconômicas, de gestão, demográficas e de cobertura de serviços de saneamento.

A Tabela 1 apresenta as variáveis que compõem o banco de dados para os domicílios urbanos e municípios de Minas Gerais. Explicitase a função da variável na pesquisa, na perspectiva da modelagem estatística, se resposta ou explicativa.

A variável resposta 'presença de coleta dos resíduos sólidos no domicílio' foi elaborada a partir da variável original do Censo Demográfico, intitulada 'Destino dos resíduos sólidos no domicílio', agregando-se as categorias originais em apenas duas categorias de interesse: 'tem coleta' e 'não tem coleta'. A primeira foi constituída apenas pelo destino original denominado 'coletado', enquanto a segunda agregou os demais destinos ('caçamba', 'queimado', 'enterrado', 'jogado no terreno', 'jogado em curso de água', 'outros').

Considerou-se o quesito 'caçamba' como parte da categoria dos resíduos sólidos domiciliares não coletados, tendo em vista que tal destino está, em grande medida, associado às áreas de ocupação urbana precárias, onde falta infraestrutura viária adequada à passagem do veículo coletor, o que representa uma diferenciação socioeconômica em relação à prestação dos serviços públicos municipais.

As demais variáveis tiveram as categorias criadas a partir da distribuição dos dados em quintis, com exceção da variável 'anos de estudo do chefe de domicílio', que seguiu a classificação observada na literatura, na qual a conclusão de um nível é o fator que indica a mudança de categoria (REZENDE et al, 2007; RIANI; RIOS-NETO, 2007).

Com os bancos de dados domiciliar e municipal devidamente estruturados, procedeu-se à análise descritiva das variáveis, visando ao conhecimento e à interpretação dos principais parâmetros estatísticos e também das distribuições de frequência de cada categoria. Além disso, foi feita a associação entre cada variável explicativa e a variável resposta, de maneira a se obter um entendimento preliminar sobre o papel de cada um dos determinantes dos serviços públicos de coleta domiciliar dos resíduos sólidos. A análise descritiva teve papel importante no estudo, pois, além de possibilitar a seleção das variáveis e categorias uma a uma, trouxe um esboço das grandes desigualdades e diferenciações existentes entre os domicílios e municípios mineiros em relação ao serviço público de interesse.

As técnicas de regressão linear e logística foram utilizadas conforme o caráter da variável resposta: se 'numérica contínua', ou 'categorizada binária', respectivamente (Tabela 2).

As análises iniciaram-se com a etapa de regressões simples, para cada variável explicativa em separado, adotando-se a análise do valor de $\mathrm{p}$, onde a variável prosseguiria se $\mathrm{p} \leq 0,20$. Em seguida, foram realizadas as análises com as regressões múltiplas, fazendo interagir o conjunto das variáveis domiciliares e municipais. O nível de significância estatística adotado nestas regressões foi o valor tradicional de $5 \%(\alpha=0,05)$.

A fim de identificar os efeitos da multicolineariedade entre as variáveis municipais, realizaram-se os testes de correlação Kendall's tau_b e rho de Spearman. Com isso, foi possível obter elementos que auxiliaram na escolha das variáveis e categorias que continuariam na análise.

A modelagem hierárquica associou as variáveis explicativas demográficas, geográficas, socioeconômicas e de gestão à variável resposta 'presença de coleta dos resíduos sólidos no domicílio', agregou os dados domiciliares e municipais selecionados em análises anteriores, tratando-os em uma análise de regressão logística com distintos níveis hierárquicos. Além da obtenção da equação do modelo a partir dos coeficientes calculados, a modelagem hierárquica permitiu o cálculo das razões de chances (Odds Ratio) de cobertura do serviço de coleta relativas a uma determinada categoria de referência para cada variável explicativa. O critério de definição da categoria de referência de cada variável explicativa partiu da interpretação dos resultados das análises descritivas e de regressão, escolhendo-se a categoria mais desfavorável em termos da cobertura associada. Em relação ao procedimento de centralização das médias das variáveis explicativas, adotou-se a centralização na 'média do grupo' para as unidades domiciliares e a centralização na 'média geral' para os municípios (RAUDENBUSH; BRYK, 2002).

O primeiro modelo hierárquico elaborado foi o denominado modelo nulo, constituído apenas pela variável resposta 'presença de 
Tabela 1 - Variáveis domiciliares e municipais segundo categorias de análise e fontes de dados

\begin{tabular}{|c|c|c|}
\hline Variável & Categorias & Fonte dos dados básicos \\
\hline $\begin{array}{l}\text { Presença de coleta dos resíduos sólidos no domicílio } \\
\text { (resposta) }\end{array}$ & $\begin{array}{l}\text { Tem } \\
\text { Não tem }\end{array}$ & IBGE, Censo Demográfico de 2000 \\
\hline Renda agregada do domicílio (em salários mínimos) & $\begin{array}{c}\text { Até } 1,5 \\
1,5 \text { a } 3,0 \\
3,0 \text { a } 5,0 \\
5,0 \text { a } 9,0 \\
\text { Acima de } 9,0\end{array}$ & IBGE, Censo Demográfico de 2000 \\
\hline Número de moradores do domicílio & $\begin{array}{c}\text { Até } 2 \\
3 \text { a } 4 \\
5 \\
\text { Acima de } 5\end{array}$ & IBGE, Censo Demográfico de 2000 \\
\hline Anos de estudo do responsável & $\begin{array}{c}\text { Até } 1 \\
2 \text { a } 3 \\
4 \text { a } 7 \\
8 \text { a } 10 \\
\text { Acima de } 10\end{array}$ & IBGE, Censo Demográfico de 2000 \\
\hline Ligação em sistema de coleta de esgotamento sanitário & $\begin{array}{l}\text { Tem } \\
\text { Não tem }\end{array}$ & IBGE, Censo Demográfico de 2000 \\
\hline IDH municipal & $\begin{array}{l}\text { Alto } \\
\text { Médio }\end{array}$ & $\begin{array}{l}\text { PNUD/IPEA/FJP, Atlas do Desenvolvimento Humano } \\
\text { no Brasil }\end{array}$ \\
\hline PIB per capita municipal (em R\$) & $\begin{array}{c}\text { Até } 2.200,00 \\
2.200,00 \text { a } 2.700,00 \\
2.700,00 \text { a } 3.500,00 \\
3.500,00 \text { a } 4.700,00 \\
\text { Acima de } 4.700,00\end{array}$ & FJP, planilhas no endereço eletrônico da instituição \\
\hline Porte populacional do município (habitantes) & $\begin{array}{c}\text { Até } 5000 \\
5001 \text { a } 10000 \\
10001 \text { a } 20000 \\
20001 \text { a } 50000 \\
50001 \text { a } 100000 \\
100001 \text { a } 500000 \\
\text { Acima de } 500000\end{array}$ & IBGE, Censo Demográfico de 2000 \\
\hline Mesorregião de localização do município & $\begin{array}{c}\text { Campo das Vertentes } \\
\text { Central Mineira } \\
\text { Jequitinhonha } \\
\text { Metropolitana de Belo Horizonte } \\
\text { Noroeste de Minas } \\
\text { Norte de Minas } \\
\text { Oeste de Minas } \\
\text { Sul/Sudoeste de Minas } \\
\text { Triângulo Mineiro/Alto Paranaíba } \\
\text { Vale do Mucuri } \\
\text { Vale do Rio Doce } \\
\text { Zona da Mata }\end{array}$ & IBGE, Censo Demográfico de 2000 \\
\hline
\end{tabular}

Tabela 2 - Características das análises de regressão

$\begin{array}{llll}\text { Técnica de regressão } & \text { Variável resposta } & \text { Caráter da resposta } & \text { Variáveis explicativas } \\ \text { Logística } & \begin{array}{l}\text { Presença de coleta domiciliar } \\ \text { dos RSU }\end{array} & \text { Binária } & \text { Domiciliares e municipais } \\ \text { Linear } & \begin{array}{l}\text { Percentual de RSU coletados } \\ \text { no município }\end{array} & \text { Numérica } & \text { Municipais }\end{array}$


coleta dos resíduos sólidos no domicílio'. A partir do modelo nulo, é possível prever o coeficiente de intracorrelação, cuja função é quantificar a parcela da variabilidade total da presença de coleta que se deve à atuação das variáveis municipais.

O procedimento seguinte correspondeu à construção do modelo completo de nível 1, com todos os determinantes domiciliares selecionados em análise de regressão prévia. Segundo Raudenbush e Bryk (2002), a realização de uma análise hierárquica pressupõe que não existe dúvida em relação à significância das variáveis de nível 1 , aspecto que foi assumido nesta modelagem. A regressão logística hierárquica avançou com alterações apenas relacionadas à entrada e à saída das variáveis do nível municipal, de maneira a se obter o melhor modelo em termos de ajuste dos dados e da capacidade de explicação das variáveis.

Os coeficientes estimados no modelo final foram analisados, interpretando-se as razões de chance, que forneceram o quadro geral do papel e do peso de cada determinante na situação da cobertura do serviço de coleta. Na análise de adequação dos modelos, verificou-se a significância de cada uma das categorias ( $\mathrm{p} \leq 0,05)$; e também as deviances e a variabilidade explicada pelas variáveis do nível municipal nos modelos, por meio de comparação. O primeiro conceito retrata o ajuste do modelo aos dados e sua capacidade preditiva (quanto menor o valor da deviance, mais ajustado é o modelo). Já o segundo indicador trata do peso que o nível municipal adquire no modelo, quantificando sua atuação na variabilidade dos dados agregados.

Como equação geral para a modelagem hierárquica temos a Equação 1 .

$\mathrm{E}(\mathrm{Yij} \mid \mathrm{x})=\pi(\mathrm{x})=\frac{\mathrm{e}^{\mathrm{g}(\mathrm{x})}}{1+\mathrm{e}^{\mathrm{g(x)}}}$

Equação 1

Em que $\mathrm{E}($ Yij $\mid \mathrm{x})$ representa a esperança matemática para a presença de coleta de lixo no i-ésimo domicílio do j-ésimo município e $\mathrm{g}(\mathrm{x})$ é o termo denominado logito, podendo ser expandido para a forma algébrica (Equação 2).

$g(x)=\operatorname{In}\left[\frac{\pi(x)}{1-\pi(x)}\right] \beta_{0}+\beta_{1} x_{1}+\beta_{2} x_{2}+\ldots+\beta_{p} x_{p}$

Equação 2

$\mathrm{Na}$ Equação 2, $\beta_{0}, \beta_{1}, \beta_{2}, \ldots, \beta_{\mathrm{p}}$ são os coeficientes associados às variáveis explicativas de $1^{\circ}$ nível $\left(\mathrm{x}_{1}, \mathrm{x}_{2}, \ldots, \mathrm{x}_{\mathrm{p}}\right.$ - domiciliares $)$, a serem obtidos a partir de regressão utilizando-se o método da 'máxima verossimilhança'. Esses coeficientes carregam em si a junção com o $2^{\circ}$ nível - municipal, o que pode ser visto a partir da Equação 3.

$\beta_{\mathrm{p}}=\gamma_{\mathrm{p} 0}+\sum \gamma_{\mathrm{pj}} \mathrm{W}_{\mathrm{j}}+\mathrm{u}_{\mathrm{pj}}$

Equação 3

A Equação 3.3 representa como se processa a integração entre as variáveis explicativas dos dois níveis: $\gamma_{\mathrm{pj}}$ são os coeficientes do segundo nível; $\mathrm{W}_{\mathrm{j}}$ são as variáveis do $2^{\circ}$ nível - municipais; e $\mathrm{u}_{\mathrm{pj}}$ são os efeitos aleatórios relativos ao segundo nível (HOSMER; LEMESHOW, 1989; RAUDENBUSH; BRYK, 2002).

\section{Resultados e discussão}

\section{Panorama da prestação dos serviços de coleta e disposição final dos resíduos sólidos urbanos de Minas Gerais (2000)}

De acordo com a PNSB de 2000 (IBGE, 2000B), a maioria absoluta dos municípios mineiros apresenta a esfera municipal como entidade prestadora dos serviços de limpeza urbana e de coleta de RSU. Em relação à constituição jurídica da entidade, verifica-se o caráter majoritário da categoria 'administração direta'.

No que se refere à arrecadação municipal, o que se gasta com serviços públicos de limpeza urbana representa muito pouco, sendo que aproximadamente $89 \%$ das prefeituras gastam apenas cerca de 5\% do que arrecadam com tais serviços. A cobrança pelos serviços públicos, quando é feita, tem sido frequentemente realizada junto com o IPTU. Em 2000, 53\% dos municípios mineiros adotavam esta prática contra $43 \%$ das municipalidades que não adotavam nenhum tipo de cobrança (IBGE, 2000B)

O tempo de emancipação política do município apresenta uma correlação direta com a cobertura de coleta de RSU. Dados do Anuário Mineiro dos Municípios de 2006 (ASSOCIAÇÃO MINEIRA DE MUNICÍPIOS, 2006) revelam que municípios recém-emancipados (até 4 anos) possuem, em média, cerca de $66 \%$ de cobertura de coleta de RSU, enquanto em municípios com mais de 65 anos de emancipação, esta cobertura se aproxima dos $86 \%$. Tal resultado sugere que a independência política das localidades é fator importante na promoção e execução das ações de saneamento, corroborando a constatação de que os serviços relativos aos resíduos sólidos em Minas Gerais apresentam caráter predominantemente local e público. A participação e a consequente exigência maior das populações por melhores condições de vida, junto aos seus governantes locais, podem incidir no aumento da cobertura dos serviços públicos municipais.

As informações dos Censos Demográficos de 1991 e 2000 mostram que a evolução do percentual de coleta domiciliar de RSU aumentou significativamente, em Minas Gerais, de 66 para 87\%, valor superior ao crescimento da média nacional, que passou de 72 para $85 \%$. O Estado conseguiu ampliar a cobertura de coleta de RSU em 21\% no período intercensitário, enquanto a Região Sudeste e o País apresentaram elevações de 10 e 13\% em suas coberturas médias, respectivamente.

Em relação à distribuição dos municípios mineiros segundo as categorias do percentual de RSU urbanos coletados, duas questões se destacam: a considerável proporção de municípios (cerca de 40\%) com mais de $90 \%$ de cobertura; e a menor, porém significativa parcela de municípios com menos de 50\% de coleta (aproximadamente 15\% dos municípios) 
Da análise do IDH municipal (PNUD/IPEA/FUNDAÇÃO JOÃO PINHEIRO, 2000) também se apreende o grande diferencial existente na cobertura da coleta domiciliar dos RSU com baixo, médio e alto IDH. Existe uma tendência clara dos municípios mais desenvolvidos a apresentarem as menores carências no acesso ao referido serviço público. Estas análises levam a um questionamento sobre as causas de tal realidade de desigualdade entre as municipalidades do Estado.

Também notaram-se diferenciais elevados entre as categorias extremas das variáveis 'porte populacional e grau de urbanização', reforçando a hipótese de que a cobertura de serviço de coleta de RSU foi determinada pelo recente processo de urbanização do País, que favoreceu a concentração populacional em núcleos urbanos polarizadores

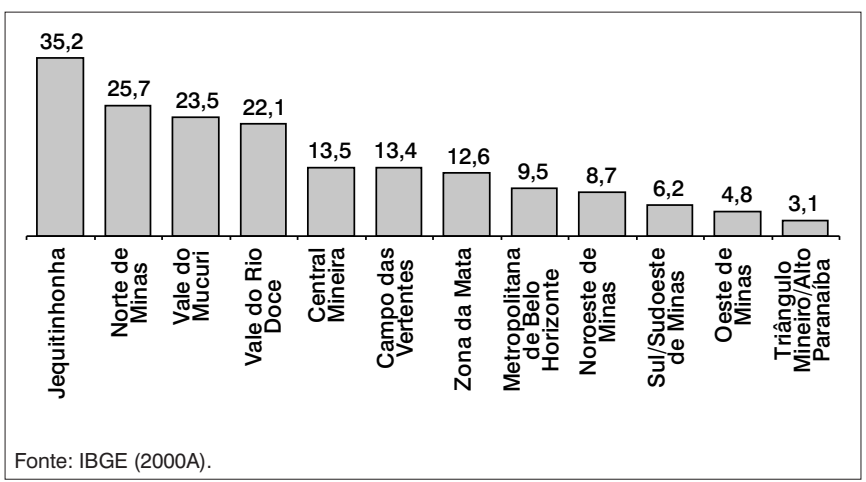

Figura 1 - Minas Gerais, 2000: percentual de ausência de coleta de RSU segundo mesorregiões de planejamento

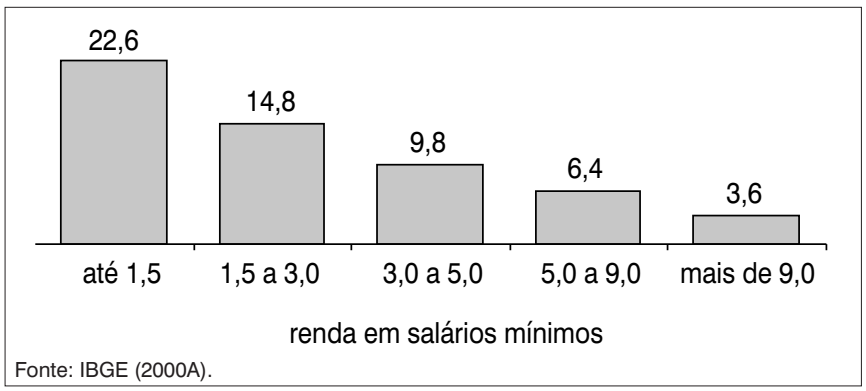

Figura 2 - Minas Gerais, 2000: percentual de ausência de coleta domiciliar de RSU segundo renda domiciliar

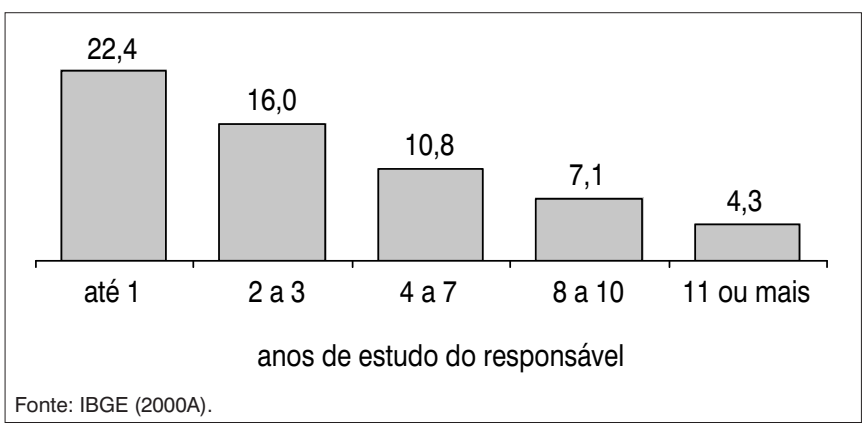

Figura 3 - Minas Gerais, 2000: percentual de ausência de coleta domiciliar de RSU segundo anos de estudo do chefe de domicílio ou ao redor destes. Quanto mais populoso e urbanizado o município, maior a cobertura do serviço público de coleta de RSU (IBGE, 2000A). Tal contexto contrasta com a distribuição da população entre os municípios mineiros, pois estes são, em sua maioria (54\%), de pequeno porte (com até 5 mil habitantes na área urbana).

Em análise do destino dos RSU segundo mesorregiões mineiras de planejamento, verificaram-se amplos diferenciais inter-regionais no Estado, com as regiões dos vales dos rios Doce, Mucuri e Jequitinhonha e a região Norte de Minas apresentando as maiores carências em relação à coleta domiciliar. Nestas mesorregiões, verificam-se elevados percentuais de resíduos sólidos queimados ou jogados no próprio terreno do domicílio ou em terrenos próximos a ele, o que tem sido causa cada vez maior de danos ambientais, aumentando os riscos potenciais que ameaçam a saúde pública (Figura 1).

Algumas das variáveis demográficas, provenientes do Censo Demográfico de 2000 (IBGE, 2000A) também demonstraram uma relação com a presença de coleta de RSU em Minas Gerais. A cobertura é mais baixa em domicílios com um número maior de moradores (seis ou mais), o que talvez esteja associado à maior fecundidade verificada entre mulheres mais pobres e menos escolarizadas, havendo também uma tendência à existência de um número maior de agregados no domicílio, visto que a renda domiciliar é fator essencial à sobrevivência de seus membros.

No que concerne às variáveis 'cor da pele' e 'estado civil' dos chefes de domicílio, as categorias brancos/amarelos e casados/viúvos/ divorciados apresentam maiores percentuais de cobertura de coleta domiciliar. As categorias menos privilegiadas estão, em geral, associadas à população de menor poder aquisitivo, seja em função do processo histórico da exclusão social e do passado escravista do País, seja em função da etapa do ciclo de vida em que se encontram os chefes de domicílio, já que nas idades mais jovens, as pessoas geralmente estão no início da vida profissional e, portanto, auferindo menor rendimento.

As variáveis socioeconômicas apresentam gradientes bastante claros em sua distribuição segundo as categorias de análise, como mostram as Figura 2 e 3. Ao se analisar a relação entre as variáveis 'coleta dos RSU' e 'renda agregada domiciliar', verifica-se um elevado diferencial na ausência de cobertura entre os quintis extremos de renda (da ordem de seis vezes). O acesso ao serviço de coleta segundo a escolaridade do chefe de domicílio é bastante variável entre as categorias extremas (da ordem de cinco vezes). Mais uma vez, evidencia-se a exclusão social, pois os extratos menos escolarizados são, em conjunto, os mais pobres e também aqueles que habitam as áreas urbanas mais precárias.

A relação entre a cobertura da coleta de RSU e a presença de bens e serviços nos domicílios urbanos também se afigura quando é observada a existência de alguns bens de consumo e serviços essenciais. A ausência de coleta domiciliar é bem maior nos domicílios que não possuem geladeira, televisão, iluminação e/ou telefonia. 


\section{Modelagem hierárquica}

O resultado final da modelagem hierárquica é apresentado na Tabela 3. Todas as categorias se mostraram significativas no que diz respeito ao valor de $\mathrm{p}$, com exceção de duas, pertencentes à variável 'mesorregiões'.
A análise das razões de chances das variáveis demográficas comprovou os resultados de Rezende (2005), que demonstram a importância dos aspectos demográficos como fatores determinantes da demanda de serviços coletivos de saneamento. Domicílios chefiados por mulheres de cor branca ou amarela têm chances 18\% maiores em relação às chances de domicílios chefiados por homens de cor preta

Tabela 3 - Modelo hierárquico final

\begin{tabular}{|c|c|c|c|c|}
\hline Variável & Categorias & p-valor & Coeficiente & Razões de chance \\
\hline \multirow[t]{2}{*}{ Presença de coleta domiciliar dos RSU (resposta) } & Tem & & & \\
\hline & Não tem & & & \\
\hline \multirow[t]{2}{*}{ Sexo do responsável } & Masculino & & Referência & \\
\hline & Feminino & 0,00 & 0,16 & 1,18 \\
\hline \multirow[t]{2}{*}{ Cor do responsável } & Preta / parda & & Referência & \\
\hline & Branca / amarela & 0,00 & 0,17 & 1,18 \\
\hline \multirow[t]{5}{*}{ Anos de estudo do responsável } & Até 1 & & Referência & \\
\hline & 2 a 3 & 0,00 & 0,17 & 1,18 \\
\hline & 4 a 7 & 0,00 & 0,36 & 1,43 \\
\hline & 8 a 10 & 0,00 & 0,54 & 1,71 \\
\hline & 11 ou mais & 0,00 & 0,68 & 1,98 \\
\hline \multirow[t]{2}{*}{ Abastecimento de água } & Não tem & & Referência & \\
\hline & Tem & 0,00 & 1,03 & 2,81 \\
\hline \multirow[t]{2}{*}{ Esgotamento sanitário } & Não tem & & Referência & \\
\hline & Tem & 0,00 & 1,61 & 5,00 \\
\hline \multirow[t]{5}{*}{ Renda agregada do domicílio } & Até 1,5 & & Referência & \\
\hline & 1,5 a 3,0 & 0,00 & 0,21 & 1,23 \\
\hline & 3,0 a 5,0 & 0,00 & 0,43 & 1,54 \\
\hline & 5,0 a 9,0 & 0,00 & 0,67 & 1,95 \\
\hline & Mais de 9,0 & 0,00 & 0,96 & 2,60 \\
\hline \multirow[t]{4}{*}{ Número de moradores do domicílio } & 6 ou mais & & Referência & \\
\hline & 5 & 0,00 & 0,16 & 1,17 \\
\hline & 3 a 4 & 0,00 & 0,25 & 1,28 \\
\hline & Até 2 & 0,00 & 0,21 & 1,24 \\
\hline \multirow[t]{5}{*}{ PIB per capita } & Até $2.200,00$ & & Referência & \\
\hline & $2.200,00$ a $2.700,00$ & 0,02 & 0,45 & 1,57 \\
\hline & $2.700,00$ a $3.500,00$ & 0,00 & 1,06 & 2,89 \\
\hline & $3.500,00$ a $4.700,00$ & 0,00 & 1,26 & 3,54 \\
\hline & Mais de $4.700,00$ & 0,00 & 1,54 & 4,66 \\
\hline \multirow[t]{6}{*}{ Porte populacional } & Até 5.000 & & Referência & \\
\hline & 5.001 a 10.000 & 0,00 & 0,46 & 1,59 \\
\hline & 10.001 a 20.000 & 0,01 & 0,48 & 1,61 \\
\hline & 20.001 a 50.000 & 0,02 & 0,55 & 1,74 \\
\hline & 50.001 a 100.000 & 0,03 & 0,68 & 1,97 \\
\hline & mais de 100.000 & 0,00 & 1,16 & 3,19 \\
\hline \multirow[t]{11}{*}{ Mesorregião de Minas Gerais } & $\begin{array}{c}\text { Norte de Minas / Vale } \\
\text { do Rio Doce }\end{array}$ & & Referência & \\
\hline & Jequitinhonha & 0,12 & 0,40 & 1,49 \\
\hline & Central Mineira & 0,22 & 0,42 & 1,52 \\
\hline & Campo das Vertentes & 0,08 & 0,54 & 1,72 \\
\hline & $\begin{array}{c}\text { Metropolitana de Belo } \\
\text { Horizonte }\end{array}$ & 0,01 & 0,59 & 1,80 \\
\hline & Vale do Mucuri & 0,02 & 0,87 & 2,38 \\
\hline & Zona da Mata & 0,00 & 0,96 & 2,60 \\
\hline & Noroeste de Minas & 0,00 & 1,40 & 4,06 \\
\hline & Oeste de Minas & 0,00 & 1,70 & 5,45 \\
\hline & $\begin{array}{c}\text { Triângulo Mineiro/Alto } \\
\text { Paranaíba }\end{array}$ & 0,00 & 2,08 & 7,99 \\
\hline & Sul/Sudoeste de Minas & 0,00 & 2,52 & 12,41 \\
\hline
\end{tabular}

Fonte: IBGE (2000A); PNUD/IPEA/Fundação João Pinheiro (2003); Associação Mineira de Municípios (2006). 
ou parda. O número médio de moradores por domicílio também apresentou correlação com a presença de serviço de coleta. A chance de cobertura é inferior em domicílios com mais de cinco moradores.

Em relação à chefia feminina, Rezende (2005) interpreta a sua superioridade na cobertura como uma conseqüencia da maior atenção por parte das mulheres às questões relativas à qualidade de vida nos domicílios. Questões de gênero, como a maternidade, fazem com que as mulheres sejam mais sensíveis às questões sanitárias. No que concerne à cor da pele, é notório que o nível socioeconômico mais baixo esteja associado aos chefes de cor preta e parda, pela condição escrava que assumiram seus antepassados em um passado relativamente recente no País.

As variáveis socioeconômicas que caracterizam a demanda, representadas pelos anos de estudo do chefe de domicílio e pela renda agregada domiciliar, revelam gradientes muito bem definidos entre as suas categorias extremas. Enquanto a chance de chefes de domicílio com escolaridade mais elevada representa o dobro da chance de domicílios cujos chefes são analfabetos ou semialfabetizados, a renda agregada apresenta uma variação das chances igual a 2,6 vezes. $\mathrm{Na}$ perspectiva da oferta, as razões de chances de coleta de RSU associadas ao PIB per capita municipal também revelam um nítido gradiente que aumenta com o aumento do PIB. Como apontado por Costa (2007), Dias, Borja e Machado (2004) e Lopes, Macedo e Machado (2003), a população excluída do acesso aos serviços de saneamento é composta, preponderantemente, por pessoas com nível socioeconômico mais baixo e que habitam áreas de ocupação espontânea. Isso mostra como os padrões de desigualdades são determinados pela distribuição espacial da população, e como a situação da coleta de RSU reflete esta realidade.

As variáveis domiciliares 'presença de serviços de abastecimento de água e esgotamento sanitário' mostraram uma forte correlação com a presença de serviço de coleta de RSU. O fato de um domicílio possuir ligação de rede de água quase triplica a sua chance de ter coleta de RSU. Se um domicílio possui ligação de esgoto, sua chance de ter acesso ao sistema de coleta é cinco vezes a chance de um domicílio sem ligação. Esse fenômeno é parcialmente explicado pela elevada cobertura de redes de água em áreas urbanas do Estado, bem mais próxima da universalização do que a cobertura de redes de esgotos.

Existe, nos grandes centros urbanos, um contingente significativo de pessoas que não usufruem dos serviços públicos de saneamento. A ausência da universalização está associada às desigualdades que pairam sobre aspectos relacionados à oferta dos serviços de saneamento, incapaz de atender completamente à demanda por razões que ultrapassam a existência dos sistemas de abastecimento de água e esgotamento sanitário. A não adesão, por parte da população, aos sistemas coletivos demonstra que os aspectos inerentes à demanda destes sistemas são de fundamental importância, pois são os fatores culturais e socioeconômicos da população, capazes de motivar a negação do uso de sistemas coletivos de saneamento. Esta ainda é uma situação que se reproduz nas periferias das grandes cidades, habitada pela população mais pobre e onde é forte a presença de imigrantes rurais e de cidades de menor porte.

A presença de coleta domiciliar de RSU em cidades com mais de 100 mil habitantes apresenta uma chance 3,2 vezes maior do que a chance de municípios com menos de 5 mil habitantes. Este resultado reafirma a ideia de D'Almeida (2000), que pressupõe uma situação mais favorável de coleta por parte dos municípios maiores, sendo que, a despeito dos maiores desafios relacionados ao manejo dos resíduos sólidos de uma parcela elevada da população, há uma tendência ao maior dinamismo econômico. Ao contrário, são as cidades menores que mais enfrentam carências de todas as naturezas, principalmente as financeiras e administrativas.

Uma grande variação foi observada nas razões de chance concernentes às mesorregiões do Estado, sendo as chances referentes às regiões Sul e Sudeste 12 vezes a chance da categoria de referência representada pelas regiões Norte de Minas e vale do Rio Doce. Na mesorregião metropolitana de Belo Horizonte, a chance de os domicílios serem atendidos por serviço de coleta é cerca de 80\% superior à da categoria de referência. Esta é uma chance consideravelmente pequena quando comparada à dos panoramas mais favoráveis. Pode-se inferir que, mais uma vez, as desigualdades sociais afetam a distribuição da presença de coleta, visto que a região metropolitana possui um contingente populacional significativo de pessoas que habitam favelas e periferias urbanas e não contam com serviços públicos de coleta.

Como sugerem Heller e Castro (2007), é cada vez mais necessária a compreensão dos condicionantes sistêmicos das políticas públicas e de seus beneficiários. É impossível alcançar a universalização dos serviços de saneamento sem a consideração dos processos sociais, políticos, econômicos, culturais e demográficos aliados aos aspectos tecnológicos. Os resultados deste estudo corroboram com a visão de Heller e Castro (2007), pois a importância das variáveis relativas aos diversos aspectos da demanda e da oferta de serviços de coleta de RSU reforça a importância de perspectivas distintas e complementares. Entende-se que apenas com a integração dessas perspectivas nas discussões em prol da universalização é que se tornará possível a proposição de soluções que consigam eliminar o déficit de cobertura dos serviços públicos.

A Tabela 4 apresenta os resultados das análises de adequação da modelagem hierárquica. Em relação ao coeficiente de intracorrelação, quase $79 \%$ da variabilidade na presença de coleta dos RSU se deve à atuação das variáveis municipais. Quanto aos valores da deviance, o modelo final completo se destaca com o valor mais baixo, demonstrando o melhor ajuste aos dados e maior capacidade preditiva em comparação aos demais modelos. Além disso, a integração dos níveis domiciliar e municipal é bem significativa, já que o nível 2 completo responde por cerca de $43 \%$ da variabilidade existente no agregado. 
Tabela 4 - Análise da adequação dos modelos hierárquicos

\begin{tabular}{lccc}
\hline Modelo hierárquico & Deviance & Variabilidade explicada pelo nível 2 (\%) & Coeficiente de intracorrelação (\%) \\
\hline Nulo & 305.190 & - & 78,98 \\
\hline Nível 1 & 269.002 & - & - \\
\hline Nível 1 + porte populacional & 242.911 & 8,20 & - \\
\hline Nível 1 + mesorregiões & 236.204 & 35,20 & - \\
\hline Nível 1 + PIB per capita & 211.376 & 29,80 & - \\
\hline Nível 1 + nível 2 completo & 201.611 & 42,70 & - \\
\hline
\end{tabular}

Fonte: IBGE (2000A); Fundação João Pinheiro (2006); Associação Mineira de Municípios (2006).

Os resultados da modelagem hierárquica demonstram a prevalência do nível municipal sobre o domiciliar no que se refere à situação da cobertura da coleta domiciliar dos resíduos sólidos urbanos em Minas Gerais. Rezende (2005) chegou a uma constatação semelhante, em que as variáveis municipais também prevaleceram sobre as domiciliares no momento da análise dos determinantes da presença de redes de água e esgoto nos domicílios brasileiros. A despeito da importância das variáveis relativas à demanda de coleta de resíduos, representadas pelas variáveis domiciliares, verifica-se o aspecto central da política pública de saneamento, na qual a atuação do poder público possui ampla relevância no alcance de cenários favoráveis à presença dos serviços essenciais nas residências urbanas.

\section{Conclusões}

Minas Gerais é um estado brasileiro que apresenta grande diversidade entre os seus municípios constituintes, possuindo realidades muito diferentes no que diz respeito aos aspectos sociais, demográficos, políticos e econômicos. Tal característica ficou clara após a análise descritiva das variáveis eleitas para explicar a demanda e a oferta dos serviços de limpeza urbana, o que também ficou constatado nas modelagens. Especificamente em relação aos resíduos sólidos domiciliares, tem-se uma grande diferenciação intraestadual tanto em relação à coleta domiciliar quanto no que diz respeito à disposição final dos resíduos sólidos urbanos nos municípios.

A modelagem hierárquica agregou os níveis domiciliar e municipal, fornecendo um cenário mais completo para o entendimento do papel dos determinantes da cobertura do serviço público de coleta domiciliar. No modelo final, foram as variáveis municipais as que mais se destacaram, em conjunto com a variável domiciliar relativa ao esgotamento sanitário. Esta variável, juntamente com o PIB per capita e as mesorregiões do Estado, foram as que apresentaram os maiores diferenciais entre as categorias extremas, revelando uma variabilidade mais acentuada em relação aos quesitos econômico, geográfico e de saneamento.
Tais resultados permitem delinear o perfil dos excluídos do acesso ao serviço de coleta domiciliar e à disposição final adequada dos resíduos sólidos: aqueles que representam a parcela mais pobre e menos escolarizada da população, com acesso limitado também ao conhecimento, à saúde e à dignidade. São os habitantes das precárias periferias urbanas das grandes metrópoles e das pequenas cidades das mesorregiões Norte, Jequitinhonha, Vale do Mucuri e Vale do Rio Doce aqueles que se encontram mais distantes da universalização das condições de cidadania e que estão menos sujeitos às ações coletivas de responsabilidade do Estado.

Pode-se dizer que a exclusão sanitária é a negação da cidadania e que ela difere da pobreza por conter elementos éticos e culturais traduzidos na discriminação e na estigmatização. A pobreza pode criar tanto uma situação absoluta quanto relativa de ausência de capacidade aquisitiva, seja de bens materiais ou não. A exclusão social, por sua vez, faz referência a categorias atingidas pelo abandono, pela perda de vínculos e das relações de convívio coletivo sadio.

O Estado brasileiro consolida uma dada concepção de inclusão que não tem garantido os direitos sociais em suas ações. Mas a exigência de padrões mínimos de sobrevivência precisa fazer parte do padrão de dignidade que a sociedade quer ver reconhecido entre seus pares. Sem dúvida, os governos, enquanto entes de administração dos serviços essenciais, devem consolidar tais garantias, que são perdidas na medida em que a exclusão representa uma perda virtual de uma condição nunca antes atingida e não uma perda real capaz de sensibilizar a sociedade.

Por fim, é preciso enfatizar que as desigualdades geradoras da referida exclusão sanitária, e que limitam o acesso de uma significativa parcela da população do Estado de Minas Gerais aos serviços de coleta de resíduos sólidos urbanos, somada à ausência da sua disposição final adequada, tem se refletido, cada vez mais, nas desigualdades do acesso a um ambiente natural e saudável. A realização de políticas setorializadas específicas pode ser um primeiro passo valioso, mas ainda ineficaz, enquanto não se puder construir uma abordagem integrada tanto em termos espaciais quanto em termos da abrangência social e política. 


\section{Referências}

ASSOCIAÇÃO MINEIRA DE MUNICÍPIOS. Anuário mineiro de municípios, 2006. Belo Horizonte: Associação Mineira de Municípios, 2006.

BRASIL. Lei 11.445, de 5 de janeiro de 2007. Diretrizes Nacionais do Saneamento Básico. Brasília: Diário Oficial da União, 2007.

Constituição da República Federativa do Brasil. Brasília: Senado Federal, 2005.

BROLLO, M.J.; SILVA, M.M. Política e gestão ambiental em resíduos sólidos. Revisão e análise sobre a atual situação no Brasil. In: $21^{\circ}$ CONGRESSOBRASILEIRODEENGENHARIASANITÁRIAEAMBIENTAL, João Pessoa, Paraíba, ABES, 2001. Disponível em: http://www.bvsde. paho.org/bvsaidis/brasil21/vi-078.pdf. Acesso em 13 jul. 2009.

COSTA, S.S. A visão da ASSEMAE sobre os principais aspectos conjunturais que interessam ao Saneamento Ambiental nos municípios brasileiros. 2006. Disponível em: http://www.assemae.org.br/novo/ibam. htm Acesso em 30 mai. 2007.

D'ALMEIDA, M.L.O. (Coord.) Lixo municipal: manual de gerenciamento integrado. São Paulo: IPT/CEMPRE, 2000

DIAS, M.C.; BORJA, P.C.; MORAES, L.R.S. Índice de salubridade ambiental em áreas de ocupação espontânea: um estudo em Salvador - Bahia. Engenharia Sanitária e Ambiental, v. 9, n. 1, p. 82-92, jan./mar. 2004.

FUNDAÇÃO JOÃO PINHEIRO. Planilha com os valores do PIB per capita dos municípios de Minas Gerais. 2006. Disponível em: http://www.fjp.

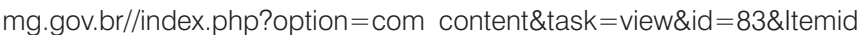
=96. Acesso em 13 abr. 2007.

HELLER, L. Who really benefits from environmental sanitation services in the cities? An intra-urban analysis in Betin, Brazil. Environmental and Urbanization, v. 11, n. 1, p. 133-144, Apr. 1999.

HELLER, L.; CASTRO, J.E. Política pública de saneamento: apontamentos teórico-conceituais. Engenharia Sanitária e Ambiental, v. 12, n. 3, p. 284295, jul./set. 2007

HELLER, L.; CATAPRETA, C.A.A. Associação entre coleta de resíduos sólidos domiciliares e saúde, Belo Horizonte (MG), Brasil. Revista Panamericana de Salud Publica I Pan American Journal of Public Health, v. 5, n. 2, p. 88-96, 1999.
HOSMER, D.W.; LEMESHOW, S. Applied logistic regression. New York: John Wiley \& Sons Inc., 1989.

INSTITUTO BRASILEIRO DE GEOGRAFIA E ESTATÍSTICA (IBGE). Censo demográfico de 2000: dados da amostra. Rio de Janeiro: IBGE, 2000A.

Pesquisa Nacional de Saneamento Básico de 2000: dados da amostra. Rio de Janeiro: IBGE, 2000B.

LOPES, H.M.; MACEDO, P.B.R.; MACHADO, A.F. Indicador de pobreza: aplicação de uma abordagem multidimensional ao caso brasileiro. Textos de Discussão. CEDEPLAR/UFMG. Belo Horizonte, 2003. Disponível em: http://www.cedeplar.ufmg.br/pesquisas/td/TD\%20223.pdf. Acesso em 2 jul. 2007.

MONTEIRO, J.H.P. et al. Manual de gerenciamento integrado de resíduos sólidos. Rio de Janeiro: IBAM, 2001.

PNUD/IPEA/FUNDAÇÃO JOÃO PINHEIRO. Atlas do desenvolvimento humano no Brasil 2003. Belo Horizonte: Fundação João Pinheiro, 2003.

RAUDENBUSH, S.W.; BRYK, A.S. Hierarchical linear models: applications and data analysis methods. Thousand Oaks: Sage Publications Inc. 2002

REZENDE, S.C. Aspectos demográficos da cobertura de serviços de saneamento no Brasil urbano contemporâneo. 157 f. Tese (Doutorado em Demografia) - Centro de Desenvolvimento e Planejamento Regiona de Minas Gerais, UFMG, Belo Horizonte, 2005.

Conseqüências das migrações internas nas políticas de saneamento no Brasil: uma avaliação crítica do PLANASA. In: XIII ENCONTRO DA ASSOCIAÇÃO BRASILEIRA DE ESTUDOS POPULACONAIS, ABEP, Ouro Preto, 2002. Disponível em: http://www. abep.nepo.unicamp.br/docs/anais/pdf/2002/GT_MIG_PO51_Rezende_ texto.pdf. Acesso em 13 jul. 2009.

REZENDE, S. et al. Integrando oferta e demanda de saneamento: análise hierárquica do panorama urbano brasileiro no ano 2000. Engenharia Sanitária e Ambiental, v. 12, n. 1, p. 90-101, jan./mar. 2007.

RIANI, J.L.R.; RIOS-NETO, E.L.G. Análise do dividendo demográfico na matrícula escolar no Brasil numa abordagem hierárquica e hierárquica espacial. Revista Brasileira de Estudos Populacionais, v. 24, n. 1, p. 6990, jan./jun. 2007. 